\title{
Quality of life on climacteric nursing professional
}

\author{
Qualidade de vida de profissionais de enfermagem no climatério
}

\author{
Calidad de vida de profesionales de enfermería en el climaterio
}

Thamyres Campos Fonsêca ${ }^{1}$, Mariana Nepomuceno Giron ${ }^{1}$, Lina Márcia Miguéis Berardinelli ${ }^{1}$, Lucia Helena Garcia Penna ${ }^{1}$

The climacteric has some unique features, especially related to body function, where women experience changes of several orders, then, it is important to study the quality of life of climateric nursing professionals. It was proposed to analyze the impact of climacteric on the quality of life of nursing professionals who work directly with care. Through an exploratory, descriptive study developed with nine nursing professionals under climacteric in a University Hospital of Rio de Janeiro, RJ, Brazil, in 2010, we proceeded to collect data through semi-structured interviews and the results were submitted to content analysis. All respondents experience changes in their quality of life after 35 years of age, at work, concerning eating, leisure activities, physical activities and other habits and lifestyles. It was concluded that climacteric affects the quality of life of nursing professionals in relationships, at work, concerning eating, physical activities, sleeping patterns and leisure.

Descriptors: Quality of Life; Nursing; Climacteric.

O climatério apresenta algumas particularidades em relação ao funcionamento corporal, as mulheres vivenciam mudanças de diversas ordens, sendo importante estudar a qualidade de vida de profissionais de enfermagem no climatério. Propôs-se a analisar a repercussão do climatério na qualidade de vida de profissionais de enfermagem que atuavam diretamente na assistência. Por meio de estudo exploratório, descritivo, desenvolvido com nove profissionais de enfermagem no climatério em Hospital Universitário do Rio de Janeiro, RJ, Brasil, em 2010, procedeu-se à coleta de dados, por meio de entrevista semiestruturada, submetidos à análise de conteúdo. As entrevistadas vivenciavam mudanças na qualidade de vida após os 35 anos, no trabalho, na alimentação, nas atividades de lazer e físicas, entre outros hábitos e estilos de vida. Conclui-se que o climatério interfere na qualidade de vida de profissionais de enfermagem em suas relações pessoais, no trabalho, na alimentação, na atividade física, no padrão de sono e lazer.

Descritores: Qualidade de Vida; Enfermagem; Climatério.

El climaterio tiene particularidades en relación con la función del cuerpo, las mujeres experimentan cambios de diversas órdenes, siendo importante estudiar la calidad de vida de profesionales de enfermería en el climaterio. Se propuso analizar las repercusiones del climaterio en la calidad de vida de profesionales de enfermería que trabajan directamente en la atención. A través de estudio exploratorio, descriptivo, desarrollado con nueve profesionales de enfermería en Hospital Universitario del Rio de Janeiro, RJ, Brasil, en 2010, se recopilaron los datos por medio de la entrevista semiestructurada, sometidos a análisis de contenido. Los encuestados experimentaban cambios en la calidad de vida después de 35 años, en el trabajo, alimentación, actividades de ocio, física, entre otros hábitos y estilos de vida. El climaterio afecta la calidad de vida de profesionales de enfermería en sus relaciones personales, trabajo, actividad física, estándar del sueño y ocio.

Descriptores: Calidad de Vida; Enfermería; Climaterio.

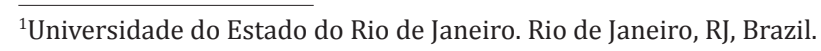

Corresponding author: Thamyres Campos Fonsêca

Est. Adhemar Bebiano, 4441 - Bl.09/102. CEP: 20765-171 - Inhaúma, RJ, Brazil. E-mail: thamyresodonto@gmail.com.br 


\section{Introduction}

In all stages of life, women experience physical, emotional and psychic alterations, whether during adolescence or in their adult life, during climacteric or senescence. The climacteric covers one of those periods of transition in which are characterized for hormonal alterations that can generate from menstrual irregularities to amenorrhea. During this period, the woman can clinically present signs and related symptoms such as those organic changes.

The changes present in the period of climacteric occur due to several factors which vary from alterations in the individual basal hormonal levels to the way these women experience this period. Therefore, during this period, the adoption of measures promoting quality of life through healthy habits such as balanced food, adequate physical activity, proactive posture facing life, capacity to elaborate projects, cultural, social, professionals, ludic and leisure activities are able to provide health and well-fare to any woman, at any $\operatorname{age}^{(1)}$.

The climacteric covers the age range between 35 and 65 years of age, representing in the year 2007, around $32 \%$ of the female population. In this period of life, the women presented expected alterations, but they need a following-up. However, it must be more directed to the understanding of their moment of life and the best way to experience it. In order to have such understanding, the woman needs to be empowered and perceive the climacteric as a natural transition ${ }^{(1)}$.

Climacteric comes from the Greek Klimactoni which means crisis and during the $1^{\text {st }}$ World Congress of Climacteric in 1976; the International Society of Menopause defined as the official concept for climacteric as the period of the life of a woman in which the transition from the reproductive phase to the non-reproductive one, occurs as well as the menopause as the interruption of menstruation, for at least twelve consecutive months ${ }^{(2)}$.

However, climacteric and menopause do not characterize a disease but only a phase of transition in the life of a woman. A great part of these women do not present any complaints or make use of alternative procedures to face this period, others develop just a few symptoms which are variable and normally not permanent. This period coincides with the moment of existential crises of the woman. She questions her social, conjugal, professional and spiritual relations ${ }^{(3)}$.

In a certain way, climacteric and the process of aging go together. And it is common to think that after menopause, the woman loses her youth and her virility. What is actually observed in this stage of life is that the women feel misinformed and unprepared for such reality ${ }^{(4)}$.

Climacteric, for being a period full of transformations in the life of the woman, whether in the professional domains, in the family area or in sexuality, can be a powerful stressing factor, provoking alterations in the self-esteem of the woman ${ }^{(5)}$.

Currently, from the changes of the Brazilian socio-demographic profile, this period in the life of the woman acquires a great relevance, not only due to a greater life expectancy of the women, but also for being a period where the woman is still economically active. Due to the larger number of women in the age range of climacteric and to the consequences of such period on the transformations in the female body, measures to promote health become necessary, aiming at the quality of life they had before, such measures must be implemented before, during and after climacteric ${ }^{(1)}$.

When discussing on a greater expectancy of life we must not leave aside the Quality of Life which is a 'wide concept, influenced in a very complex manner by multiple factors, among them: the psychological state, the level of independence, the social relations, the characteristics of the environment and the physical health'(6:3). This concept includes, among other factors, the quality of life related to the work and to the influence which the endocrinal modifications of the ovarian failure can have on the quality of life perceived by the women.

With the development of the studies concerning health, the topic 'quality of life' has become a target of 
interest of researches. This is due to possible beneficial results that the researches in this area can provide, contributing to evaluate the cost-benefit relation to the service rendered, to help define treatment and guide the follow-up of the patient ${ }^{(7)}$. And although the topic 'quality of life' is incessantly approached in society, many do not know the real meaning of having healthy habits and style of life.

After many years of discussions and the fact that many authors have their own concept, they have come to an agreement, up to the present moment, which can adequately conceptualize the term 'quality of life'. Among other concepts, quality of life can be defined as the perception of the subject in his position in life under the context of culture and systems of values in which he lives, concerning his targets, expectations, standards and worries. Other aspects are referred to such as: the physical and psychological domains, the social relations, the environment and the spiritual aspects $^{(8-9)}$.

Other concepts define quality of life under three fundamental aspects: subjectivity, multidimensionality and the presence of positive dimension (e.g.: mobility) and negative ones (e.g.: pain). These aspects should be able to measure the quality of life anywhere in the planet. The definition of quality of life following those aspects can be enounced as the perception of the subject of his position in life, in a context of culture and system of values in which he lives, concerning his goals, expectations, standards and worries ${ }^{(7)}$.

The term quality of life represents the decision of the human being must take regarding his health, concerning leisure, food habits, behaviors with his social cultural variables thus being under his control. Nevertheless, the liberty of choice of the subjects on their own styles of life, is, in a great part, conditioned by the social environment in which the subject is inserted $^{(10)}$.

The satisfaction with health is one of the fundamental components of the quality of life perceived, and that is why a term was proposed to adequate the definition of the contents of the concept of quality of life: quality of life regarding health ${ }^{(6)}$.

Once the term quality of life is full of subjectivity, one of its determinants is the work and it uses a fundamental space in the life of the human being inserted in the contemporaneous society. Many problems of health are especially resulting from the weariness and stress which are reflexes of the condition of life. The authors still add that even the health professionals will do not undergo health treatment in a systematized way ${ }^{(11-12)}$.

A punctual question generally found in the studies which approach the topic, is the reflection of the relation of the conditions of work on the quality of life of the subjects. The work, which is a source of pleasure and satisfaction, is, however, a need of survival for the vital condition of all human beings. It is essential to life and to the happiness of people. Studies have especially shown that the repercussions from work have caused damage to the health and the life of people, such as the high use of muscle force and the excessive waste of physical energy that generates problems of posture and general fatigue in the workers, dissatisfaction due to low salaries requiring the agreement of a double or triple journey of work, high exposition to the risk offered by the hospital environment, decreasing the time for leisure, among others $^{(13)}$.

The concept of quality of life in the work depends on factors such as: motivation, satisfaction, health and security at work. Besides that, the topic covers discussions concerning the organization at work and possible technologies ${ }^{(7)}$.

In general, the health professionals are submitted to very long working hours and to many wearing activities. This is added to the small number of professionals and psycho- emotional weariness experienced in the hospital environment.

In a bibliographical research, a vast number of articles published regarding nursing quality of life are found. This is justified by the fact that nursing is directly related to the process of prevention, 
promotion and protection of health which is closer to the aimed quality of life. The absence of articles regarding the quality of life in nursing versus the relation with the climacteric (period of the female vital cycle) should be highlighted.

The physical overload which the nursing professionals are submitted to, are determinant factors for the outcome of osteoarticular problems and the smaller the intervals the professional has during his working journey, the lower is the outbreak. The night shifts and the sleeping problems generate family problems, depressive conditions, gastric problems caused by a long period without eating or by irregular intervals among the meals. Concerning the social environment, the low salaries and limited access to leisure constitute a source of anguish and possible source of psychiatric disorders ${ }^{(14)}$.

The conditions of vulnerability at work bring the possibility of understanding situations experienced by the nursing professionals in hospital institutions which generally generate repercussions along their lives. Many times, the peculiarity of the type and rhythm of work unleashes stress, pain, suffering, physical weariness, caused by the hospital environment itself in dealing with patients with different clinical conditions and in the situation which the SUS (Unified Health System) goes through, e.g., the difficult to supply human and material resources.

Together with this labor situation, the climacteric is presented as a period where the body, hormonal and social alterations, which requires physical, psychological and emotional adaptations also aggravates old feelings and conflicts which may be re-lived in this stage $\mathrm{e}^{(1)}$.

When climacteric comes, the women face the reality that around one third of their lives is available and that must be lived the best possible way. The standard of beauty imposed by the society and the youth culture associated to the success, affect the woman's self-esteem and there is a repercussion on their professional and personal relations. Adding to that, there is the difficult insertion and maintenance in the work market and the economical difficulties caused by the prejudice regarding old age $\mathrm{e}^{(12)}$.

According to that, being a nursing professional workingintheirprofessionalactivitiesincircumstances which are adverse to health, as previously mentioned, having a duplicity in the roles of their daily life, besides the double and/or triple working hours and undergoing the period of climacteric, will certainly make alterations in the quality of life brought by the association of these situations.

In this context, the women experience changes concerning several orders in this period of life. It is important to study the quality of life of the nursing professionals during climacteric.

Keeping in mind the limitation of the object of this study, the guiding question which directed this study was: in which way do the alterations of climacteric influence in the quality of life of the nursing professionals who act directly in assistance? And for the development of the study we have determined an objective: to analyze the repercussions of climacteric in the quality of life of nursing professionals who act directly in assistance.

\section{Method}

The qualitative approach of the descriptiveexploratory type was chosen. The research was developed in a University Hospital in the county of Rio de Janeiro, Brazil, 2010. We have chosen as interviewees the nursing professionals working in two clinical units and two surgical units, among those: Medical Clinic Ward, Urology ward, Gynecology ward and Center of Intensive General Therapy. The subjects of the study were nine nursing professionals; of those six were nursing technicians and three nurses who work at the units described above, in the morning and afternoon shifts and a schedule for nightshift.

The criteria of inclusion of the subjects were: nursing professionals, within the age range between 35 and 65 years of age, according to the definition established by the Health Department for the period 
of climacteric ${ }^{(1)}$, interested in participating voluntarily in the study.

The technique of data collection was through individual semi-structured interview, following a previously elaborated script and made up of four open main questions and eight complementary ones.

The interviews were recorded in a MP3 device and later on, fully transcript and organized in chronological order. The data produced were submitted to the technique of analysis of contents following the necessary steps: floating reading of all the material in order to reach the general idea of the data; identification of the relevant contents, that is, the sections which marked the statements, either for being similar or for being different ${ }^{(15)}$.

Afterwards, these contents were separated by units of registers, originating the emergent category called body alterations, resulting from climacteric presented by the women of the nursing team.

This research was made complying with Resolution 196/96 of the National Council of Health, which guides the results with the participation of human beings. Following those purposes, the project was submitted to the analysis of the Committee of Ethics in Research of the University Hospital and its development was authorized according to protocol no. 2569-CEP/HU-CAAE: 0008.0.228.0010. All the participants, after knowing the objectives of the study, voluntarily accepted to take part in it, besides confirming their formal acceptance signing the Informed Consent Form (ICF). In order to keep the anonymity of the participants, they were given Brazilian gems pseudonyms.

\section{Results}

When analyzing the statements of nine nursing professionals interviewed, there were six nursing technicians and six nurses; we consider presenting the socio cultural characteristics of the group studied in order to deepen the analysis of the categories resulting from the statements.
In order to provide a better presentation of the data, we divided the age of the interviewees by age range in an interval of ten years, being five women between 35 and 45 years of age, three women between 46 and 55 years and one woman between 55 and 65 years of age.

Regarding the level of schooling, five professionals had High School and four have University Degree in the area of health. Of those professionals, five work in Surgical Clinic and four in Medical Clinic. Regarding the time of work in that function, it varied from 5 to 33 of work. When questioned on the number of working places, three of them stated to have two or three jobs.

So, the following category was defined: repercussions of the climacteric in the quality of life of the professional nursing women. The interviewees stated how their habits and styles of life were before the climacteric and if there were any changes after their beginning. The name of the category is justified by the fact that it was noticed throughout the statements of the nursing professionals, that all the interviewees experienced changes in their quality of life after 35 years of age, whether regarding the work, the pattern of sleeping, food, leisure, the practice of physical activities among other habits and styles of life considered in this study.

Regarding the changes in the quality of life, it was identified that all the participants perceived significant changes from 35 years of age on, whether they were at work, during leisure time, regarding food, pattern of sleeping, among others. And that the signs and symptoms resulting from the reduction of the woman's hormonal production (nursing professionals), during climacteric, somehow interfered in their professional daily work, according to the following statements: I think it influences everything. Even in the relation with the patient, in the relation with the team, I am very excited, very anxious and during this period I become twice or more so than what I already am. And sometimes I don't even have time to stop, to provide assistance to my team. So, it is a day that you think you are going to do things and you get more tired and you 
don't do it. Because you want to see everything at the same time and you can't see anything concerning quality (Esmeralda). I went back to therapy precisely because of that, so that I would not interfere on my own relations. Because with my patients I had no problem. I had to work all of this out not to cause any embarrassment with my colleagues (Água- Marinha). You try to preserve as much as you can not to mix things and not bringing this to your work. That is all. Actually, you get a little more irritated, but then you learn to live with all of that and of course you are in a period which makes you more irritated, you tend to be more on your own (Ametista).

As to work, it must be highlighted that some of the participants feel more tired and unwell. Added to that, the exhaustive nursing working hours, the double jobs, besides other activities performed by the women at home.

As to the practice of physical exercises, several women stated to be sedentary, something justified by the lack of time. The day I wouldn't go to the gym I would walk, walked a little... distance I don't know, but I walked well, more than one hour, two hours. Now I don't do any of this (Pérola). I am really sedentary (Safira).

However, two of them reported having physical activities for quite a long time, and one of those started only after the beginning of the climacteric, showing significant improvement on the emotional matters and pattern of sleeping. I felt a lot of difference after I started hydrogym. Because the greater liberation, this emotional question, I put into practice during my physical exercise. When I do hydro, I felt like light (Esmeralda).

Among the participants there was the recognition of non healthy food habits, including here some who had started dyspepsia after 35 years of age. The statements which followed were grouped for having common characteristics and for exemplifying food habits that jeopardize the quality of life of the nursing professionals. Irregular food, you don't have time to eat, real food, but when I am at home, at least on evening, I try to eat healthy food, because on the weekend ... (Ametista). I was never the kind who eats in the street, but let's suppose: today, if I go to a Mac Donald's, the food doesn't do me well. I do not have a good digestion, maybe because I stopped moving a little. Then I have to eat more fruit, more vegetables, lighter food (Rubi). Eating too fast, always eating too fast. Until today I eat in a rush, and there was still the course, then I would eat very badly (Granada).

Regarding leisure, there were women that did not spend time with those moments, most of them justify that due to the lack of time. I have very little time. It is because I never went out much anyway, I had a baby too soon, I was 19 and when I was 21, I was bringing up children, then I went to work, and that is it, there isn't much more no (Topázio). I used to go out a lot, but now I am quiet, stay home at night, but due to the lack of time (Pérola). It's been a long time that I don't know what leisure is, just work. Before I had time to go out, I would walk, have physical activities, understood? Today I don't (Ônix).

However, some professionals recognized that after 35 years, they have found more time for leisure and entertainment. Now I have more time, my children are married, and now my husband and I date more (Safira).

Concerning the pattern of sleeping, there were reports of difficulty to sleep and they reported insomnia. You have no sleeping pattern, you end up sleeping late, waking up early, not because of lack of sleep, but due to the lack of chance to actually sleep (Ametista). I sleep very well, I work a lot, but when I have the opportunity to sleep, I sleep (Topázio).

Regarding the noxious habits to health, there were women who smoked and drink alcoholic beverages.

\section{Discussion}

We understand that the topic quality of life is very wide, which makes its approach difficult and because it is a completely private and personal concept, in which the following factors infer: family, person and environmental satisfaction sustained in the concepts imposed by society to the subject.

Perceiving that most of the interviewees report that their work routine has been altered by the symptoms of the climacteric and understanding that the work relations direct influence in the life of the human being and that the nursing profession imposes a high load of work, with many responsibilities and many ethic moral precepts to be faced daily; we consider the work as a participant factor in the quality 
of life.

Both the nurse and the woman when following the global evolutional processes have been conquering the work market, assuming leadership and assuming leading positions which were exclusive to men. Such positioning subdivides the woman into fundamental roles: being an independent worker, being a mother, a wife, and the role of being only and exclusively a woman. So many tasks associated to the fact of working in nursing being physically and emotionally wearisome directly affect the quality of life of these women.

Concerning the area of work, factors such as health, motivation, satisfaction and security, as well as new technology inserted in the market and the new organization of the work, interact with the quality of life at work ${ }^{(16)}$.

The symptoms of climacteric interfere in the professional activity, whether by physical tiredness, or by alterations of humor or even difficulty of relationship with the team or the patient.

Another factor which came up was the long working hours to which the women (nursing professionals) are submitted to in order to guarantee better wages. Such journey before bravely complied with by them, today shows to be impossible both by the tiredness of their old age, as well as by the symptoms resulting from the climacteric, e.g. headaches and pain in the lower limbs and the emotional and the emotional instability.

The hospital itself is an unhealthy environment which offers danger to those who work there. Besides the risks of physical accidents to which the workers are constantly submitted, the psychic suffering is also frequent, especially for the climacteric women, once many times they are emotionally fragile ${ }^{(12)}$.

Regarding the physical activities, most of them reported not to exercise. This sedentarism is many times justified by the lack of time. The physical exercises, when regularly practiced, can promote welfare, and improve self-esteem, decrease anxiety, tension and depression. Currently, there is an expressive association between a healthy style of life, a smaller possibility of developing degenerative chronic diseases and a better quality of life. But we understand, with the way of life of the current society, time available for such activities has become each time shorter ${ }^{(1)}$.

Another aspect of the style of life of those women was the eating habits. Of all the interviews analyzed we noticed that some interviewees reported to have unhealthy food habits. For most of them, the justification was their own daily routine of contemporaneous woman, who does not have adequate time for the meals, which again characterizes the work as a participative factor in the quality of life of these women.

Regarding the difficulty of digestion of the food, among the interviewees, there was dyspepsia showing the need to eat healthier food, such as, green leaves, fruits and vegetables, as well as food which make the digestive process easier. Therefore, it is learned from the statements of the participants that, besides not presenting a good digestive process, there was also no time available for the meals during the daily journey of work, having an undesirable repercussion in the nutritional aspects, consequently, declining their quality of life.

Food is certainly one of the important items in the life of women and have the aim at providing adequate ingestion of calories, proteins, fat, calcium, vitamins and minerals which are essential to the maintenance of health, adequate weight, of bone mass and to the cardiovascular protection ${ }^{(1)}$.

Concerning the moment dedicated to leisure, we observed that a significant number of interviewees reported not having time for leisure activities resulting from their daily life occupations. Activities of leisure as going to the beach, to the theater, to the cinema, to the park, among others, provide moments of relaxation, of entertainment and the experiences with the family and friends which undoubtedly improve the quality of life of the women during climacteric.

However, it was observed that, after the 
beginning of the climacteric, there was more time dedicated to leisure, once the children were already independent and there weren't so many worries with their homes so that they now could 'enjoy life more'.

Concerning the pattern of sleeping, we noticed that most of the nursing professionals reported not having any difficulty to sleep. The interviewees justified such behavior with the triple routine of work (hospital, children and husband), which makes them weary enough to have a quite night sleep.

It was also understood that the pattern of sleeping suffers more interferences from the journey of work than the climacteric itself. The women reporting not having an adequate or established schedule for rest, which show totally irregular patterns of sleeping. Added to that there is the usual tiredness of the long day of work plus the unusual tiredness of the climacteric and once again, the work of nursing as an influent factor in the quality of life of the female nursing professional is evident.

Obesity, sedentarism, hypertension, besides tobacco and alcohol are risk factors which favor the occurrence of cardiovascular diseases. The changes in the food habits, physical activity and reduction of tobacco, provide substantial change in the rates of chronicle diseases. Thus, the women during the post-menopause period have a higher risk to develop cardiovascular diseases due to the reduction of estrogen ${ }^{(9)}$.

The harmful effects caused by tobacco and the use of alcohol in the population are widely publicized, however, it seems that this fact did not prevent the health professionals from the use of cigar or alcoholic beverages.

With the obtained data, we observe that these women acquired after the climacteric, habits and styles of life that placed at risk regarding the occurrence of non transmissible diseases. Among them, sedentarism, inadequate food habits, tobacco and alcoholism, even if it is only socially used.

The control of the several risk factors such as sedentarism, tobacco, use of alcohol beverages, among others, must be made integrally in order to prevent possible diseases. The joining of the actions adopted by the styles of life is what establishes a profile for the subject, but it is necessary to notice the risk factors in a global way without particularizing them ${ }^{(1)}$.

\section{Final Considerations}

The alterations of the climacteric have the repercussion on the life of the women under this period concerning several aspects such as: their interpersonal relations, in the roles of professionalwoman-mother-wife, discomfort with the changes in her body, her corporal image and a relation with aging.

The climacteric interferes in the quality of life of the nursing professionals, in their relations, at work, in their eating habits, in the physical activity and in the patterns of sleeping and leisure. The work is an integrating part of the quality of life of the human being and can be a source of pleasure or stress. In the case of nursing, the working journeys are exhaustive, and once associated to the changes experienced by the women in the period of climacteric, they generate conflicts sometimes in the professional/team relation, sometimes in the professional/client relation.

The hospital environment is a place where there is a psycho-emotional wearing, in factors such as irritability, change of humor and emotional instability, presented by some women under climacteric help for those conflicts to happen. We must also consider the woman-worker who, besides the double or triple working journey, also has other roles such as: mother and wife.

It is fundamental to have a differentiated look on the health professionals on this woman, privileging integral attention to her health. The departments of attention to the workers health must promote room for the discussion on subjects related to climacteric where they can expose their difficulties and ways to deal with the changes in a way so as to create a net of support among the professionals. Once these women know the modification that they will be, or 
not, exposed to, can pursuit resources, especially non allopathic ones, to deal with them.

The promotion of habits and healthy styles which include healthy and balanced food, practice of physical activities, leisure, pleasant working activity and others in the age range of the women under climacteric help in the prevention and/or the delay of the risks of non-transmissible diseases.

In order to improve the quality of life of our society, the spheres of health must have, as main objective, the construction of a model of assistance to health focused on the needs of the human being, on his fears and anxiety and on these expectations. When one is dealing in the quality of life of the woman under climacteric, the focus must be differentiated, aiming at providing information, so that the women can overcome her stigmas of aging and providing assistance for her emergent needs.

It is in this period of life that the woman faces other challenges: seeing herself as an empty nest, once their children have become independent and have left their homes; many times their conjugal relationship is weary and a renovation is needed; many are in the process of retirement. Dealing with so many innovative questions makes this period a time in which the woman can show herself more insecure, more emotionally unstable and with her sexuality affected.

This is a population which deserves to be studied more deeply for representing a great percentage of the economically active population, because the nursing profession presents a physical and emotional weary and because the higher number of nursing professionals is female.

In the pursuit of rendering adequate assistance to the woman-mother-worker-wife under climacteric, the nursing professionals, must at first get rid of prejudice. It is necessary to observe the middle-aged woman, not as a multi complaining being, but as a person who has suffered physical, psychological and social transformations.

The woman, during the period of climacteric, expresses in her daily experiences the physical and psychological alterations considered normal, and also of physiological aging, however, some are able to understand such transformations, and others become more sensitive. Facing this context, it is suggested that the area responsible for the Health of the Worker should promote discussions by groups of interests among the workers in order to help them reflect and understand the symptoms of climacteric and the process which involves human aging.

\section{Collaborations}

Fonsêca TC and Giron MN contributed for the conception of the work, data collection, analysis and interpretation of the data, writing of the article and analysis of the final version to be published. Berardinelli LMM contributed for the conception of the work, analysis and interpretation of the data and writing of the article. Penna LHG contributed for the conception of the work, analysis and interpretation of the data and writing of the article.

\section{References}

1. Ministério da Saúde (BR). Manual de atenção à mulher no climatério/menopausa. Brasília: Ministério da Saúde; 2008 (Normas e Manuais Técnicos - Série Direitos Sexuais e Direitos Reprodutivos).

2. Almeida LHRB, Luz MHBA, Monteiro CFS. Ser mulher no climatério: uma análise compreensiva pela enfermagem. Rev Enferm UERJ. 2007; 15(3):370-5.

3. Zampieri MFM, Tavares CMA, Hames MLC, Falcon GS, Silva AL, Gonçalves LT. O processo de viver e ser saudável das mulheres no climatério. Esc Anna Nery. 2009; 13(2):305-12.

4. Instituto Brasileiro de Geografia e Estatística. População. [internet]. 2009 [citado 2009 out 5]. Disponível em: http://www.ibge.gov.br/paisesat/ main.php

5. Oliveira DM, Jesus MCP, Merighi MAB. Climatério e sexualidade: a compreensão dessa interface por 
mulheres assistidas em grupo. Texto Contexto Enferm. 2008; 17(3):519-26.

6. Membrive JM, Molina JG, Salmerón MJS, Sola CF, López CMR, Carreño TP. Quality of life in perimenopausal women working in the health and education system. Rev Latino-Am Enfermagem. 2011; 19(6):1314-21.

7. Oliveira CJ, Pereira CAR, Pontes JNC, Fialho AVM, Moreira TMM. Análise da produção científica na área da saúde sobre qualidade de vida no Brasil entre 2000 e 2005: um estudo bibliográfico. Rev Eletr Enf [periódico na Internet]. 2007 [citado 2009 nov 10]; 9(2):496-505. Disponível em: http://www.fen.ufg.br/fen_revista/v9/n2/pdf/ v9n2a16.pdf

8. The World Health Organization quality of life assessment (WHOQOL): position paper from the World Health Organization. Social Sci Med. 1995; 41(10):1403-9.

9. Freitas GL, Vasconcelos CTM, Moura ERF, Pinheiro AKBP. Discutindo a política de atenção à saúde da mulher no contexto da promoção da saúde. Rev Eletr Enf [periódico na Internet]. 2009 [citado 2013 nov 4]; 11(2):424-8. Disponível em: http:// www.fen.ufg.br/revista/v11/n2/pdf/v11n2a26. pdf
10. Rouquayrol MZ, Gurgel M. Epidemiologia \& saúde. 7aㅡ ed. Rio de Janeiro: Medbook; 2013.

11. Valença CN, Germano RM. Concepções de mulheres sobre menopausa e climatério. Rev Rene. 2010; 11(1):161-71.

12. Reis LM, Moura AL, Haddad MCL, Vanucci MTO, Smanioto FN. Influência do climatério no processo de trabalho de profissionais de um hospital universitário público. Cogitare Enferm. 2011; 16(2):232-9.

13. Evangelista AIB, Pontes AGV, Silva JV, Saraiva AKM. A saúde do trabalhador na atenção primária à saúde: o olhar do enfermeiro. Rev Rene. 2011; 12(n. esp.):1011-20.

14. Pitta A. Hospital - dor e morte como ofício. 5a ed. São Paulo: AnnaBlume; 2003.

15. Bardin L. Análise de conteúdo. Lisboa: Edições 70; 2011.

16. Campos JF, David HMSL. Abordagens e mensuração da qualidade de vida no trabalho de enfermagem: produção científica. Rev Enferm UERJ. 2007; 15(4):584-9. 